\title{
ANALISIS METODE FMEA PADA PROSES OPERASIONAL SHIPPING DALAM PENDISTRIBUSIAN PART TOYOTA PADA PERUSAHAAN PT XYZ
}

\author{
Ayu Endah Wahyuni', Amin Rais ${ }^{2}$ \\ Program Studi Teknik Industri, Universitas Widyatama,Kota Bandung ${ }^{12}$ \\ email $^{1}$ : ayu.endah@widyatama.ac.id
}

\begin{abstract}
Abstrak
Permasalahan yang dihadapi perusahaan saat ini dalam proses distribusi adalah mengenai keterlambatan keberangkatan distribusi. Permasalahan tersebut dapat dilihat dari ketepatan waktu keberangkatan distribusi pada bulan Oktober sampai Desember 2018 yang hanya memiliki persentase ketepatan waktu sebesar 44,8\%, 68,94\% dan 78,1\% dari total distribusi pada bulan tersebut. Tujuan penelitian ini adalah melakukan perbaikan pada proses operasional shipping, karena 60\% dari keterlambatan keberangkatan disebabkan karena proses operasional. Hal tersebut dikarenakan dalam proses operasional shipping terdapat aktivitas yang tidak memberikan nilai tambah (non value added activities) sehingga membuat waktu proses menjadi lama. Perbaikan pada bagian operasional ini menggunakan metode FMEA. Hasil dari penilitian ini mengidentifikasikan jenis pemborosan (waste) yang terjadi pada proses operasional yaitu waste waiting dan waste unnecessary motion yang mengakibatkan proses operasional menjadi lebih lama. Usulan perbaikan untuk mengatasi keterlambatan keberangkatan distribusi ini yaitu dengan membuat checkheet untuk melakukan perhitungan barang yang dimuat, melakukan pemilihan vendor khusus kemasan kaca, petugas packing sebaiknya melakukan pengelompokkan barang sesuai identitas customer saat akan menyimpan barang ke troli dan melakukan pengecekan sebelum mengerjakan rute selanjutnya, menambah karyawan untuk checking atau packing chemical part, dan menambah material handling troli.
\end{abstract}

Kata kunci: Waste, Keterlambatan pengiriman, DMAIC

\section{PENDAHULUAN}

PT XYZ bergerak pada bidang logistik dengan produk utamanya adalah produk Part Toyota dan memiliki 20 rute distribusi yang digunakan untuk mendistribusikan part Toyota ke 35 customer dalam Kota Bandung dan 46 customer Luar Kota Bandung. Perusahaan menerapkan lead time satu hari untuk proses pendistribusian barangnya dari waktu penerimaan order, dan khusus untuk pemesanan mendesak dapat dilakukan distribusi pada hari yang sama.

Distribusi barang diperusahaan saat ini sering mengalami keterlambatan pada saat keberangkatan ekspedisi pengirim dari gudang, hal tersebut dapat dilihat dari ketepatan waktu keberangkatan distribusi dalam tiga bulan terakhir yaitu pada bulan oktober sampai desember 2018, dari total distribusi yang dilakukan pada tiga bulan tersebut dengan total 504 pengiriman hanya 334 keberangkatan pengiriman yang tepat waktu. Ratarata satu kali pengiriman terdapat 127 line item yang akan dikirim, artinya jika terjadi satu kali pengiriman barang yang terlambat maka barang yang terlambat adalah sebanyak 127 . Total line item barang yang mengalami keterlambatan keberangkatan distribusi pada ketiga bulan tersebut adalah sebanyak 19765 line item. Keterlambatan distribusi tersebut terjadi dikarenakan keterlambatan operasional shipping, sistem input data error dan ketelambatan kedatangan armada pengiriman. Permasalahan keterlambatan distribusi tersebut membuat barang sampai ke konsumen menjadi tidak tepat waktu dan permasalah tersebut membuat pekerja melakukan waktu lembur karena semua barang harus dikirim pada hari itu juga.

Pada bulan Oktober sampai Desember 2018 perusahaan hanya memiliki persentase ketepatan waktu sebesar $44.8 \%, 68,94 \%$ dan $78,1 \%$ dari $98 \%$ ketepatan waktu keberangkatan distribusi yang ditetapkan oleh perusahaan. Proses operasional menjadi penyebab tertinggi timbulnya keterlambatan distribusi. Proses operasional dalam distribusi barang meliputi proses picking, checking, packing, loading, dan shipping document. Proses operasional 
ini sering menyebabkan keterlambatan distribusi dikarenakan dalam proses operasional terdapat aktivitas yang tidak memberikan nilai tambah (non value added activities) sehingga membuat waktu proses menjadi lama.

Aktivitas yang tidak memberikan nilai tambah tersebut termasuk jenis pemborosan (waste). Waste tersebut merupakan aktivitas yang tidak memberikan nilai tambah dan perlu segera dihilangkan. Penggunaan metode FMEAmelakukan perbaikan untuk menggurangi terjadinya keterlambatan distribusi yang disebabkan oleh aktivitas yang tidak memberikan nilai tambah pada proses operasional shipping sehingga proses operasional shipping menjadi lebih cepat dan dapat meningkatkan kualitas distribusi perusahaan.

\section{TINJAUAN PUSTAKA \\ Pemborosan (Waste)}

Menurut Hines dan Taylor (2000), pada saat berpikir tentang pemborosan (waste), akan lebih mudah bila mendefinisikannya kedalam tiga jenis aktivitas yang berbeda yaitu:

a. Aktivitas yang Bernilai Tambah (Value Adding Activity)

Segala aktivitas yang dalam menghasilkan produk atau jasa yang memberikan nilai tambah di mata konsumen, contoh dari aktivitas tipe ini adalah mengubah plat baja menjadi tangki baja, dan lain sebagainya.

b. Aktivitas yang Tidak Bernilai Tambah (Non Value Adding Activity)

Merupakan segala aktivitas yang dalam menghasilkan produk atau jasa yang tidak memberikan nilai tambah di mata konsumen. Aktivitas inilah yang disebut waste yang harus dijadikan target untuk segera dihilangkan, contoh dari aktivitas ini adalah waktu menunggu, penumpukan bahan atau material, dan lain-lain.

c. Aktivitas yang Tidak Bernilai Tambah Tetapi Dibutuhkan (Necessary But Non Value Adding Activity)

Merupakan segala aktivitas yang dalam menghasilkan produk atau jasa yang tidak memberikan nilai tambah di mata konsumen tetapi diperlukan kecuali apabila sudah ada perubahan pada proses yang ada. Aktivitas ini biasanya sulit untuk dihilangkan dalam waktu FMEA

singkat. Contoh dari aktivitas ini adalah inspeksi

FMEA adalah prosedur yang terstruktur untuk mengidentifikasi dan mencegah sebanyak mungkin mode kegagalan (Casadai, 2007). Metode evaluasi kemungkinan terjadinya sebuah kegagalan dari sebuah sistem, desain, proses atau service untuk dibuat langkah penanganannya (Yumaida.
2011). Dalam FMEA, setiap kemungkinan kegagalan yang terjadi dikuantifikasi untuk dibuat prioritas penanganan.

Pada tahap ini usaha-usaha peningkatan kinerja kualitas produk dan juga proses dimulai dengan cara membuat FMEA (Failure Mode and Effect Analysis) dan memberikan usulan perbaikan untuk mengurangi cacat dalam proses. Suatu mode kegagalan adalah apa saja yang termasuk dalam kecacatan atau kegagalan dalam desain, kondisi diluar batas spesifikasi yang telah ditetapkan, arah perubahan-perubahan dalam produk yang menyebabkan terganggunya fungsi dari produk itu. Melalui menghilangkan mode kegagalan, maka FMEA akan meningkatkan keandalan dari produk dan pelayanan sehingga meningkatkan kepuasan pelanggan yang menggunakan produk dan pelayanan. Pada dasarnya sasaran dari proses manufaktur adalah menghasilkan produk yang memenuhi spesifikasi sepanjang waktu.

Menurut Gasperz (2002), terdapat beberapa faktor penting dalam tabel FMEA. Faktor tersebut adalah sebagai berikut:

1. Item dan Fungsi

Jelaskan deskripsi dari proses dan spesifikasispesifikasi atau referensi yang menjelaskan persyaratan-persyaratan proses.

a. Akibat Potensial dari Kegagalan

Akibat potensial adalah apa yang pengguna akhir akan mengalami sebagai hasil dari mode kegagalan. Kelompokkan akibat yang serupa atau yang memiliki akibat buruk yang sama.

b. Pengaruh Buruk atau Kefatalan (Severity)

Merupakan suatu estimasi atau perkiraan subyektif tentang bagaimana buruknya pengguna akhir akan merasakan akibat dari kegagalan itu. Severity merupakan suatu penilaian mengenai efek dari suatu kegagalan potensial yang akan berdampak pada pelanggan. Untuk mendapatkan hasil secara kuantitas diperlukan adanya rating untuk masing-masing kategori.

Tabel 1. Tabel Severity

\begin{tabular}{|c|c|c|}
\hline Ranking & Severity & Deskripsi \\
\hline 1 & $\begin{array}{c}\text { Tidak ada } \\
\text { efek }\end{array}$ & $\begin{array}{c}\text { Kegagalan tidak berdampak } \\
\text { kecil }\end{array}$ \\
\hline 3 & Kecil & $\begin{array}{c}\text { Kegagalan memberikan efek } \\
(<25 \%)\end{array}$ \\
\hline 4 & $\begin{array}{c}\text { Sangat } \\
\text { rendah }\end{array}$ & $\begin{array}{c}\text { Kegagalan memberikan efek } \\
\text { pengiriman } \\
(>75 \%)\end{array}$ \\
\hline 5 & Rendah & $\begin{array}{c}\text { Kegagalan memberikan efek } \\
\text { terhadap penurunan fungsi } \\
\text { sebagian sistem }\end{array}$ \\
\hline 6 & Sedang & $\begin{array}{c}\text { Kegagalan memberikan efek } \\
\text { terhadap hilangnya fungsi }\end{array}$ \\
\hline
\end{tabular}




\begin{tabular}{|c|c|c|}
\hline & Tinggi & $\begin{array}{c}\text { Kegagalan memberikan efek } \\
\text { terhadap penurunan fungsi } \\
\text { utama sistem }\end{array}$ \\
\hline 7 & $\begin{array}{c}\text { Sangat } \\
\text { tinggi }\end{array}$ & $\begin{array}{c}\text { Kegagalan memberikan efek } \\
\text { terhadap hilangnya fungsi } \\
\text { utama sistem }\end{array}$ \\
\hline 9 & $\begin{array}{c}\text { Berbahaya } \\
\text { dengan } \\
\text { peringatan }\end{array}$ & $\begin{array}{c}\text { Kegagalan membahayakan } \\
\text { sistem dengan adanya } \\
\text { peringatan terlebih dahulu }\end{array}$ \\
\hline 10 & $\begin{array}{c}\text { Barbahaya } \\
\text { tanpa } \\
\text { peringatan }\end{array}$ & $\begin{array}{c}\text { Kegagalan membahayakan } \\
\text { sistem tanpa adanya } \\
\text { peringatan terlebih dahulu }\end{array}$ \\
\hline
\end{tabular}

c. Penyebab Potensial dari Kegagalan

Setiap perubahan dalam variabel yang mempengaruhi proses akan menyebabkan proses itu menghasilkan produk diluar batas-batas spesifikasi. Kolom ini biasanya mendaftarkan nama-nama variabel yang terlibat dalam proses dan batas-batas operasional dari variabelvariabel itu.

d. Kemungkinan Kejadian (Occurrence)

Suatu perkiraan subyektif tentang probabilitas atau peluang bahwa penyebab itu akan terjadi, akan menghasilkan mode kegagalan yang memberi akibat tertentu. Perkiraan tersebut dapat digunakan dengan skala 1 sampai dengan 10.

Tabel 2. Occurence Index

\begin{tabular}{|c|c|c|}
\hline Rangking & Occurrence & Deskripsi \\
\hline 1 & $\begin{array}{l}\text { Tidak ada } \\
\text { efek }\end{array}$ & $\begin{array}{l}\text { Hampir tidak pernah terjadi } \\
\text { dalam sebulan }\end{array}$ \\
\hline 2 & \multirow{2}{*}{ Rendah } & $\begin{array}{c}\text { Sangat jarang terjadi dalam } \\
\text { sebulan }\end{array}$ \\
\hline 3 & & $\begin{array}{c}\text { Cukup jarang terjadi dalam } \\
\text { sebulan }\end{array}$ \\
\hline 4 & \multirow{3}{*}{ Sedang } & $\begin{array}{c}\text { Sedikit jarang terjadi dalam } \\
\text { sebulan }\end{array}$ \\
\hline 5 & & Jarang terjadi dalam sebulan \\
\hline 6 & & Sedikit sering dalam sebulan \\
\hline 7 & \multirow{2}{*}{ Tinggi } & Kegagalan yang berulang \\
\hline 8 & & Cukup sering dalam sebulan \\
\hline 9 & \multirow{2}{*}{$\begin{array}{l}\text { Sangat } \\
\text { tinggi }\end{array}$} & Sangat sering dalam sebulan \\
\hline 10 & & $\begin{array}{l}\text { Hampir selalu terjadi dalam } \\
\text { sebulan }\end{array}$ \\
\hline
\end{tabular}

(Sumber: McDermott dkk, 2009)

e. Pengendalian Sekarang

Identifikasi metode-metode yang diterapkan untuk mencegah atau mendeteksi penyebab dari mode kegagalan, contoh: spesifikasi produk, uji dan laporan laporan perhitungan, inspeksi, dan lain sebagainya.

f. Efektifitas Metode Deteksi dan Pencegahan (Detection)

Suatu perkiraan subyektif tentang bagaimana efektivitas dari metode pencegahan atau deteksi menghilangkan mode kegagalan. Skala yang digunakan yaitu 1 sampai dengan 10 yang akan ditampilkan pada Tabel 2.5 berikut:

Tabel 3. Detection-Prediction Index

\begin{tabular}{|c|c|}
\hline Rangking & Kriteria \\
\hline 1 & $\begin{array}{l}\text { Pengecekan selalu bisa } \\
\text { mendeteksi kegagalan }\end{array}$ \\
\hline 2 & $\begin{array}{l}\text { Pengecekan hampir selalu bisa } \\
\text { mendeteksi kegagalan }\end{array}$ \\
\hline 3 & $\begin{array}{l}\text { Pengecekan bisa mendeteksi } \\
\text { kegagalan }\end{array}$ \\
\hline 4 & $\begin{array}{l}\text { Pengecekan berpeluang sangat } \\
\text { besar bisa mendeteksi kegagalan }\end{array}$ \\
\hline 5 & $\begin{array}{l}\text { Pengecekan berpeluang besar bisa } \\
\text { mendeteksi kegagalan }\end{array}$ \\
\hline 6 & $\begin{array}{l}\text { Pengecekan kemungkinan bisa } \\
\text { mendeteksi kegagalan }\end{array}$ \\
\hline 7 & $\begin{array}{l}\text { Pengecekan berpeluang kecil bisa } \\
\text { mendeteksi kegagalan }\end{array}$ \\
\hline 8 & $\begin{array}{l}\text { Pengecekan berpeluang sangat } \\
\text { kecil bisa mendeteksi kegagalan }\end{array}$ \\
\hline 9 & $\begin{array}{l}\text { Pengecekan gagal sehingga tidak } \\
\text { mampu mendeteksi kegagalan }\end{array}$ \\
\hline 10 & $\begin{array}{l}\text { Kegagalan tidak mungkin } \\
\text { tedeteksi melalui pengecekan }\end{array}$ \\
\hline
\end{tabular}

(Sumber: McDermott dkk, 2009)

\section{g. Angka Prioritas Risiko (Risk Priority Number} atau $R P N$ )

Merupakan hasil perkalian antara ranking pengaruh buruk atau kefatalan (severity) dengan ranking kemungkinan kejadian (occurence) dan ranking efektivitas metode deteksi dan pencegahan (detection). Setiap mode kegagalan mempunyai satu $R P N$. Melalui menyusun $R P N$ dari yang terbesar sampai yang terkecil, maka kita akan mampu menentukan mode kegagalan mana yang paling kritis sehingga perlu mendahulukan tindakan korektif pada mode kegagalan itu. Jika terdapat lebih satu nilai kemungkinan yang berkaitan dengan penyebab tertentu, maka itu memiliki nilai $R P N$ yang sama. Masukan semua nilai $R P N$ itu, kemudian tentukan nilai rata-rata. Adapun rumus untuk menghitung $R P N$ yaitu sebagai berikut:

\section{Risk Priority Number $(\mathrm{RPN})=S X O X D$}

\section{METODOLOGI PENELITIAN}

Metodologi penelitian ini merupakan langkahlangkah yang dilakukan dalam melaksanakan sebuah penelitian. 


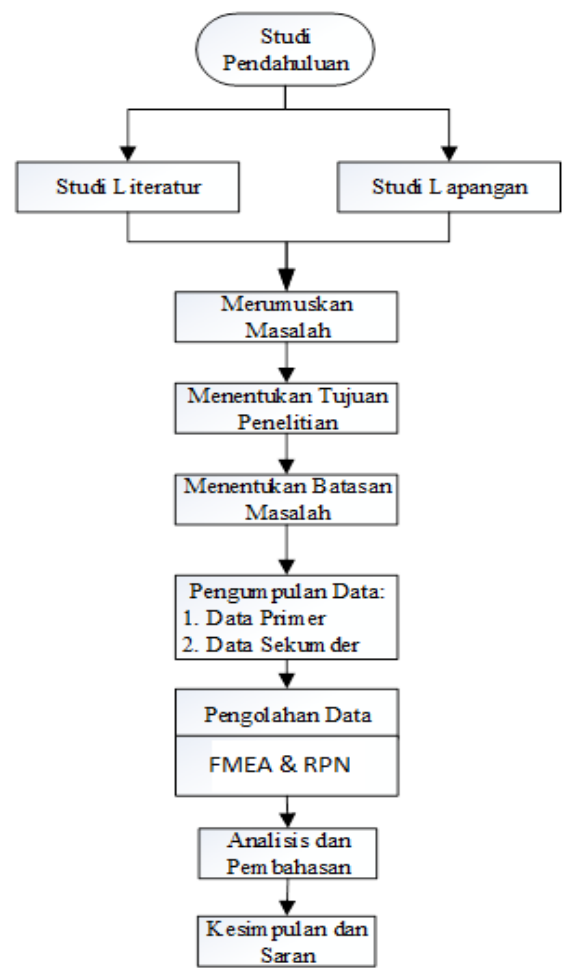

Gambar 1. Metodologi Penelitian

\section{Identifikasi Masalah}

Tahap analisis dilakukan dengan menggunakan diagram fishbone untuk mengetahui sebab dan akibat dari keterlambatan distribusi. Pembuatan diagram fishbone ini menggunakan konsep 6M yaitu machine, material, methods, man power, measurement, dan milieu atau mother nature, namun pada penelitian kali ini hanya terdapat 4 kategori yang menyebabkan keterlambatan pengiriman yaitu machine, methods, material dan man power. Hasil diagram fishbone tersebut dapat dilihat pada gambar berikut:

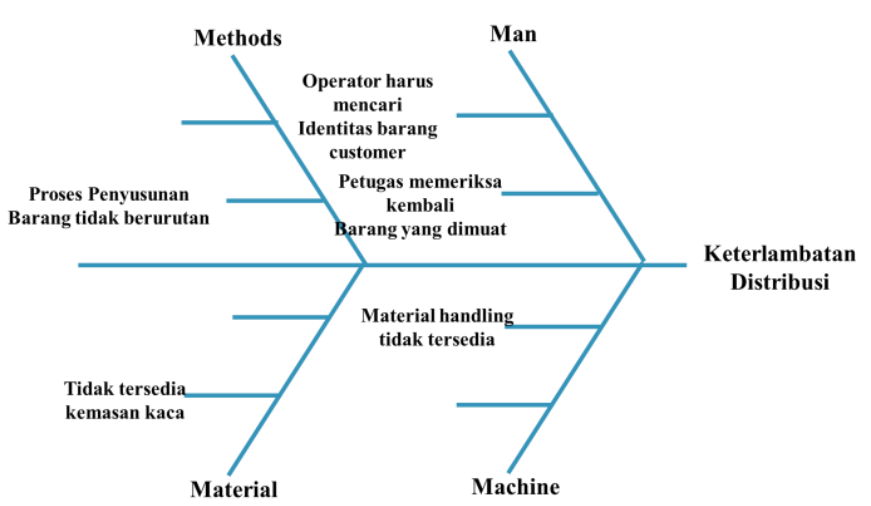

Gambar 2. Diagram Fishbone Chart

a. Faktor Manusia

Faktor manusia merupakan salah satu faktor yang menyebabkan keterlambatan. Dibawah ini merupakan penyebab terjadinya keterlambatan karena faktor manusia:

1. Petugas loading harus mencari barang sesuai identitas customer

2. Petugas harus melakukan pengecekan kembali barang yang sudah dimuat

b. Faktor Mesin

Faktor Machine dapat menyebabkan keterlambatan karena material handling kadang tidak tersedia saat ingin digunakan, hal tersebut disebabkan karena material handling digunakan secara bergantian dengan departemen lain sehingga membuat aktivitas operasional shipping harus menunggu.

c. Faktor Material

Faktor material menjadi penyebab keterlambatan karena tidak tersedianya kemasan khusus kaca. Akibat lain dari tidak tersedianya kemasan kaca ini yaitu kaca tidak dapat dilakukan pengiriman sesuai jadwal karena tidak ada ukuran kemasan yang sesuai dan akan dilakukan pengiriman pada pengiriman berikutnya sampai tersedia kemasan kaca yang sesuai.

d. Faktor Metode

Faktor method yang mempengaruhi keterlambatan pengiriman yaitu proses pengemasan barang kadang tidak sesuai dengan urutan rute, hal tersebut dikarenakan barang untuk rute tersebut belum tersedia untuk dikemas sehingga petugas melakukan pengemasan terhadap barang yang sudah siap untuk dikemas meskipun barang tersebut tidak sesuai rute.

\section{Pengolahan Data}

Tabel 4. Tabel FMEA

\begin{tabular}{|l|l|l|l|l|l|}
\hline $\begin{array}{c}\text { Type } \\
\text { Waste }\end{array}$ & \multicolumn{1}{|c|}{ Waste } & SEV & OCC & DET & RPN \\
\hline \multirow{5}{*}{$\begin{array}{l}\text { Unnece } \\
\text { ssary } \\
\text { Motion }\end{array}$} & $\begin{array}{l}\text { Petugas harus } \\
\text { mengecek } \\
\text { kembali barang } \\
\text { yang sudah di } \\
\text { muat }\end{array}$ & 2 & 2 & 2 & 8 \\
\cline { 2 - 6 } & $\begin{array}{l}\text { Petugas harus } \\
\text { mencari barang } \\
\text { sesuai identitas } \\
\text { customer saat } \\
\text { melakukan muat } \\
\text { barang }\end{array}$ & 2 & 7 & 5 & 70 \\
\hline
\end{tabular}




\begin{tabular}{|c|c|c|c|c|c|}
\hline Waiting & $\begin{array}{l}\text { Proses loading } \\
\text { harus menunggu } \\
\text { semua barang } \\
\text { selesai dikemas }\end{array}$ & 5 & 3 & 2 & 30 \\
\hline Waiting & $\begin{array}{l}\text { Proses } \\
\text { operasional } \\
\text { menjadi } \\
\text { terhambat } \\
\text { karena proses } \\
\text { pengecekan } \\
\text { chemical part }\end{array}$ & 5 & 3 & 3 & 45 \\
\hline Waiting & $\begin{array}{l}\text { Proses } \\
\text { operasional } \\
\text { menjadi } \\
\text { terhambat } \\
\text { karena } \\
\text { penggunaan } \\
\text { material } \\
\text { handling harus } \\
\text { bergantian } \\
\text { dengan bagian } \\
\text { lain }\end{array}$ & 6 & 5 & 7 & 210 \\
\hline Waiting & $\begin{array}{l}\text { Proses packing } \\
\text { dan loading } \\
\text { menjadi } \\
\text { tertunda karena } \\
\text { kemasan kaca } \\
\text { tidak tersedia } \\
\text { atau tidak ada } \\
\text { ukuran yang } \\
\text { sesuai }\end{array}$ & 7 & 5 & 7 & 245 \\
\hline
\end{tabular}

\section{ANALISIS DAN PEMBAHASAN DATA}

Proses operasi ini merupakan proses operasi yang dilakukan sebelum barang di kirim kekonsumen. Gambar 4.1 merupakan alur proses operasi shipping yang ada di Serasi Logistik Indonesia Sub Depo Bandung.

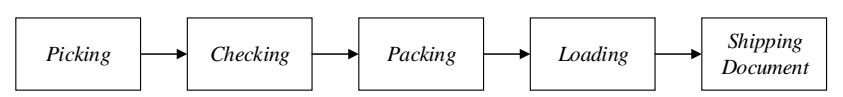

Gambar 3. Alur Proses Shipping

(Sumber: PT XYZ, 2018)

Tabel 4. Tabel FMEA (Waste)

\begin{tabular}{|c|c|c|c|c|}
\hline $\begin{array}{l}\text { Type } \\
\text { Waste }\end{array}$ & Waste & $\begin{array}{c}\text { Penyebab } \\
\text { Waste }\end{array}$ & $\begin{array}{l}\text { Pengendali } \\
\text { an sekarang }\end{array}$ & $\begin{array}{l}\text { Recommended } \\
\text { Solution }\end{array}$ \\
\hline $\begin{array}{l}\text { Unnece } \\
\text { ssary } \\
\text { Motion }\end{array}$ & $\begin{array}{l}\text { Petugas } \\
\text { harus } \\
\text { mengec } \\
\text { ek } \\
\text { kembali } \\
\text { barang } \\
\text { yang } \\
\text { sudah } \\
\text { di muat }\end{array}$ & $\begin{array}{l}\text { Kesalahan } \\
\text { dalam } \\
\text { menghitun } \\
\text { g barang } \\
\text { yang akan } \\
\text { di muat }\end{array}$ & $\begin{array}{l}\text { Perhitung } \\
\text { an } \\
\text { dilakukan } \\
\text { oleh } \\
\text { beberapa } \\
\text { orang }\end{array}$ & $\begin{array}{l}\text { Membuat } \\
\text { checksheet } \\
\text { untuk } \\
\text { mencatat } \\
\text { jumlah } \\
\text { barang yang } \\
\text { sudah } \\
\text { dimuat }\end{array}$ \\
\hline
\end{tabular}

\begin{tabular}{|c|c|c|c|c|}
\hline & $\begin{array}{l}\text { Petugas } \\
\text { harus } \\
\text { mencari } \\
\text { barang } \\
\text { sesuai } \\
\text { identita } \\
\mathrm{s} \\
\text { custome } \\
r \text { saat } \\
\text { melaku } \\
\text { kan } \\
\text { muat } \\
\text { barang }\end{array}$ & $\begin{array}{l}\text { Peletakan } \\
\text { barang di } \\
\text { troli tidak } \\
\text { dikelompo } \\
\text { kkan } \\
\text { sesuai } \\
\text { identitas } \\
\text { customer }\end{array}$ & $\begin{array}{l}\text { Petugas } \\
\text { loading } \\
\text { yang } \\
\text { bertugas } \\
\text { memisahk } \\
\text { an barang } \\
\text { sesuai } \\
\text { dengan } \\
\text { identitas } \\
\text { customer }\end{array}$ & $\begin{array}{l}\text { Petugas } \\
\text { packing } \\
\text { sebaiknya } \\
\text { langsung } \\
\text { mengelompo } \\
\text { kkan barang } \\
\text { sesuai } \\
\text { dengan } \\
\text { identitas } \\
\text { customer } \\
\text { saat } \\
\text { memasukkan } \\
\text { barang ke } \\
\text { troli cargo }\end{array}$ \\
\hline Waiting & $\begin{array}{l}\text { Proses } \\
\text { loading } \\
\text { harus } \\
\text { menung } \\
\text { gu } \\
\text { semua } \\
\text { barang } \\
\text { selesai } \\
\text { dikema } \\
\text { s }\end{array}$ & $\begin{array}{l}\text { Proses } \\
\text { packing } \\
\text { tidak } \\
\text { dilakukan } \\
\text { secara } \\
\text { berurutan }\end{array}$ & $\begin{array}{l}\text { Petugas } \\
\text { loading } \\
\text { harus } \\
\text { mengecek } \\
\text { proses } \\
\text { shipping } \\
\text { tiap rute } \\
\text { sebelum } \\
\text { loading }\end{array}$ & $\begin{array}{l}\text { Petugas } \\
\text { packing } \\
\text { sebaiknya } \\
\text { melakukan } \\
\text { pengecekan } \\
\text { pada sistem } \\
\text { GTOPAS } \\
\text { sebelum } \\
\text { mengerjakan } \\
\text { pengemasan } \\
\text { barang untuk } \\
\text { rute lain }\end{array}$ \\
\hline \multirow{3}{*}{ Waiting } & $\begin{array}{l}\text { Proses } \\
\text { operasi } \\
\text { onal } \\
\text { menjadi } \\
\text { terhamb } \\
\text { at } \\
\text { karena } \\
\text { proses } \\
\text { pengece } \\
\text { kan } \\
\text { chemic } \\
\text { al part } \\
\end{array}$ & $\begin{array}{l}\text { Proses } \\
\text { checking } \\
\text { dan } \\
\text { packing } \\
\text { chemical } \\
\text { part } \\
\text { dilakukan } \\
\text { oleh satu } \\
\text { petugas }\end{array}$ & $\begin{array}{l}\text { Melakuka } \\
\mathrm{n} \text { alokasi } \\
\text { manpower } \\
\text { lain untuk } \\
\text { proses } \\
\text { packing } \\
\text { chemical } \\
\text { part }\end{array}$ & $\begin{array}{l}\text { Menambah } \\
\text { manpower } \\
\text { atau } \\
\text { karyawan, } \\
\text { agar } \\
\text { karyawan } \\
\text { fokus ke } \\
\text { pekerjaannn } \\
\text { ya masing- } \\
\text { masing }\end{array}$ \\
\hline & $\begin{array}{l}\text { Proses } \\
\text { operasi } \\
\text { onal } \\
\text { menjadi } \\
\text { terhamb } \\
\text { at } \\
\text { karena } \\
\text { penggu } \\
\text { naan } \\
\text { materia } \\
l \\
\text { handlin } \\
g \text { harus } \\
\text { berganti } \\
\text { an } \\
\text { dengan } \\
\text { bagian } \\
\text { lain }\end{array}$ & $\begin{array}{l}\text { Keterbatas } \\
\text { an } \\
\text { material } \\
\text { handling }\end{array}$ & $\begin{array}{l}\text { Mengguna } \\
\text { kan jenis } \\
\text { material } \\
\text { handling } \\
\text { lain saat } \\
\text { terjadi } \\
\text { overload }\end{array}$ & $\begin{array}{l}\text { Menambah } \\
\text { jumlah } \\
\text { material } \\
\text { handling } \\
\text { khususnya } \\
\text { troli }\end{array}$ \\
\hline & $\begin{array}{l}\text { Proses } \\
\text { packing } \\
\text { dan } \\
\text { loading } \\
\text { menjadi } \\
\text { tertunda } \\
\text { karena } \\
\text { kemasa } \\
\text { n kaca } \\
\text { tidak } \\
\text { tersedia } \\
\text { atau } \\
\text { tidak } \\
\text { ada }\end{array}$ & $\begin{array}{l}\text { Persediaa } \\
\text { n kemasan } \\
\text { kaca } \\
\text { hanya } \\
\text { menganda } \\
\text { lkan } \\
\text { pengirima } \\
\text { n dari } \\
\text { TAM } \\
\text { SPLD }\end{array}$ & $\begin{array}{l}\text { Mengguna } \\
\text { kan troli } \\
\text { kaca dan } \\
\text { membuat } \\
\text { kemasan } \\
\text { custom }\end{array}$ & $\begin{array}{l}\text { Mengadakan } \\
\text { persediaan } \\
\text { kemasan } \\
\text { khusus kaca } \\
\text { salah satu } \\
\text { caranya } \\
\text { dengan } \\
\text { melakukan } \\
\text { pemilihan } \\
\text { vendor } \\
\text { khusus } \\
\text { kemasan } \\
\text { kaca }\end{array}$ \\
\hline
\end{tabular}




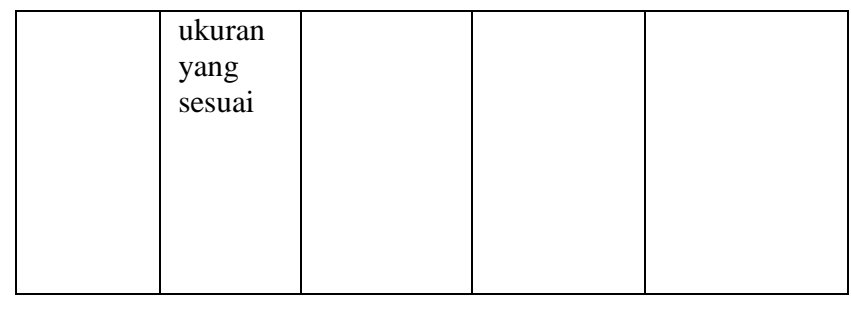

Berdasarkan tabel FMEA, diketahui ketiga waste tertinggi yang perlu segera dilakukan perbaikan. Waste pertama yang perlu dilakukan perbaikan adalah waste proses loading menjadi tertunda karena kemasan kaca tidak tersedia atau tidak ada ukuran yang sesuai. Waste kedua yang perlu dilakukan perbaikan adalah waste proses loading menjadi terhambat karena penggunaan material handling harus bergantian dengan bagian lain. Waste ketiga yang termasuk waste yang memiliki nilai $R P N$ tertinggi adalah waste petugas harus mencari barang sesuai dengan identitas customer. Adapun rekomendasi perbaikan pada ketiga waste tersebut adalah sebagai berikut:

1. Waste proses loading menjadi tertunda karena kemasan kaca tidak tersedia atau tidak ada ukuran yang sesuai

Rekomendasi perbaikan keterlambatan pengiriman karena tidak tersedianya kemasan kaca yaitu dengan mengadakan persediaan kemasan kaca dengan cara memilih vendor khusus kemasan kaca, karena untuk saat ini perusahaan hanya menggandalkan kemasan kaca dari penerimaan kaca yang dikirim oleh TAM SPLD, dan sehingga jika tidak ada persediaan kemasan kaca yang sesuai maka kaca tersebut tidak akan dikirim ke konsumen sesuai jadwal pengiriman. Pemilihan vendor khusus kemasan kaca ini dilakukan agar perusahaan terdapat persediaan kemasan kaca yang cukup dan saat ini perusahan belum bekerjasama dengan vendor khusus untuk kemasan kaca sehingga persediaan kemasan tersebut hanya bergantung pengiriman kaca dari TAM SPLD.

2. Waste proses loading menjadi terhambat karena penggunaan material handling harus bergantian dengan bagian lain

Rekomendasi perbaikan penggunaan material handling yang bergantian yaitu dengan melakukan penambahan material handling khususnya jenis material handling troli. Penambahan material handling ini dikarenakan terdapat aktivitas yang membutuhkan material handling dan aktivitas tersebut tidak dapat dilakukan jika menggunakan material handling jenis lain. Aktivitas yang membutuhkan troli tersebut biasanya terjadi pada proses picking, sparepart dan body part, hal tersebut dikarenakan bentuk dan ukuran barang tidak cocok jika mengangkut dengan menggunakan hand pallet atau forklift. Jumlah penambahan yang direkomendasikan adalah menambah 3 troli untuk proses picking. Penambahan 3 troli ini agar petugas picking tidak perlu bergantian dengan bagian storage. Jumlah troli saat ini untuk proses picking dan bining (storage) yaitu sebanyak 7 troli. Penambahan trolli tersebut membuat jumlah troli menjadi 10, dan rekomendasi penempatan troli adalah 4 troli untuk proses binning (storage) dan 6 troli untuk proses picking. Penempatan 6 troli pada proses picking karena pada proses ini terdapat 3 petugas sehingga dengan adanya 6 troli satu petugas dapat memakai dua troli dan tidak perlu bergantian dengan bagian lain.

3. Waste petugas harus mencari barang sesuai dengan identitas customer

Rekomendasi perbaikan keterlambatan pengiriman dikarenakan petugas harus mencari nama customer saat melakukan loading barang yaitu petugas packing sebaiknya langsung mengelomppokkan barang sesuai dengan identitas customer saat akan meletakkan barang di troli. Proses pengelomppokkan barang yang ada troli biasanya dilakukan oleh petugas loading, sedangkan untuk rekomendasi perbaikaan ini proses pengelompokkan barang sebaikknya dilakukan oleh petugas packing. Hal tersebut karena setelah barang selesai dikemas barang, petugas packing akan memasukkan barang kedalam troli dan saat penyusunan tersebut sebaiknya barang langsung dikelomppokkan sesuai dengan identitas customer agar petugas loading tidak perlu memilah barang saat akan melakukan muat barang.

\section{SIMPULAN}

Berdasarkan hasil penelitian pada PT XYZ mengenai proses operasional shipping dalam pendistribusian part Toyota, maka diperoleh kesimpulan yang dapat mencapai tujuan penelitian yang telah ditetapkan. Tujuan dari penelitian ini yaitu membuat usulan perbaikan pada proses operasional shipping. Usulan perbaikan pada proses operasional shipping pada PT Serasi Logistik Indonesia Sub Depo Bandung adalah sebagai berikut:

1. Usulan untuk Waste Waiting

a. Proses packing dan loading menjadi tertunda karena persediaan kemasan kaca kadang tidak tersedia untuk kaca dengan ukuran tertentu. usulan perbaikannya yaitu mengadakan persediaan kemasan khusus kaca. Salah satu cara untuk melakukan persediaan kemasan khusus kaca yaitu dengan melakukan pemilihan vendor khusus kemasan kaca sehingga dapat tersedia kemasan yang sesuai dengan ukuran kaca 
saat ada orderan kaca. Usulan ini diharapkan dapat mempercepat proses packing kaca karena tidak perlu membuat kemasan kaca, sehingga waktu packing kaca dapat berjalan dengan normal yaitu dengan waktu 1 menit. Waste ini sebaiknya segera dilakukan perbaikan karena waste ini memiliki nilai $R P N$ yang paling tinggi yaitu sebesar 245 .

b. Proses operasional menjadi terhambat karena keterbatasan material handling sehingga membuat penggunaan material handling harus bergantian. Usulan yang diberikan yaitu menambah jumlah material handling khususnya troli dikarenakan untuk proses yang menggunakan material handling troli tidak dapat diganti dengan material handling lain. Berdasarkan nilai $R P N$ pada tabel FMEA, waste ini perlu segera dilakukan perbaikan kedua setelah waste mengenai persediaan kemasan kaca. Hal tersebut dikarenakan nilai $R P N$ waste ini merupakan nilai $R P N$ tertinggi kedua yaitu sebesar 210 .

c. Proses operasional menjadi terhambat karena petugas checking chemical part harus melakukan proses checking sekaligus packing sehingga membuat petugas harus bolak-balik untuk mengerjakan kedua proses tersebut. Usulan yang diberikan yaitu menambah Manpower atau Karyawan, agar karyawan dapat lebih fokus ke pekerjaannnya masing-masing, sehingga dapat mempercepat proses chemical part. Nilai RPN waste ini adalah sebesar 45.

d. Proses loading harus menunggu semua barang selesai dikemas karena petugas packing melakukan packing untuk barang rute lain dikarenakan barang untuk rute tersebut belum tersedia atau karena petugas loading tidak tahu masih ada barang untuk rute tersebut belum dikemas. Usulan yang diberikan yaitu petugas packing sebaiknya melakukan pengecekan terhadap barang untuk rute yang akan dimuat sebelum mengerjakan proses packing rute lain agar proses operasional menjadi berurutan sehingga saat loading barang tidak harus menunggu terlalu lama. Nilai RPN waste ini adalah sebesar 30 .

\section{DAFTAR PUSTAKA}

Casadei, D., Serra, G., \& Tani, K. (2007). IEEE Transactions on Power Electronics. Implementation of a direct control algorithm for induction motors based on discrete space vector modulation, pp. 769-777.
Copra, S., \& Meindl, P. (2007). Supply Chain Management : Strategy, Planning, and Operation. 3rd ed. New Jersey: Person Education.

Copra, S., \& Meindl, P. (2010). Supply chain Management: Strategy, Planning, and Operation, 4th ed. New Jersey: Pearson Education.

Evans, J. R., \& Lindsay, W. M. (2007). An Introduction to Six sigma \& Process Improvement. Jakarta: Salemba Empat.

Frazele, E. (2002). Supply chain strategy: the logistics of supply chain management. New York: McGraw-Hill Companies.

Gaspersz, V. (2002). Pedoman Implementasi Program Six Sigma Terintregasi Dengan ISO, 9001:2000, MBNQA, dan HACCP. Jakarta: PT. Gramedia Pustaka Utama.

Gaspersz, V., \& Fontana, A. (2011). Lean Six Sigma For Manufacturing and Service Industries. Bogor: Vinchristo Publication.

Hendradi, C. (2006). Statistik Six sigma Dengan Minitab Panduan Cerdas Inisiatif Kualitas Six Sigma. Yogyakarta: Andi.

Hines, P., \& Taylor, D. (2000). "Going Lean". Lean Enterprise Research Center Cardiff Bussiness School. USA.

Hugos, M. H. (2003). Essentials of Supply chain Management. New Jersey: John Wiley \& Sons.

Intifada, G. S., \& Witantyo. (2012). Minimasi waste (Pemborosan) menggunakan Value Stream Analysis Tool untuk meningkatkan efisiensi waktu produksi. Jurnal Teknik POM ITS, Vol 1, No 1.

Kodrat, D. S. (2009). Manajemen Distribusi Berbasis Teori dan Praktek. Yogyakarta: Graha Ilm.

Li, S., Ragu-Nathan, B., Ragu-Nathan, T., \& Rao, S. (2005). Development and validation of a measurement instrument for studying supply chain management practices. Juornal of Operations Management, 618-641.

Liker, J. (2006). The Toyota Way. Jakarta: Erlangga. McDermott, R., Mikulak, R., \& Beauregard, M. (2009). The Basics of FMEA 2nd Edition. New York: Taylor \& Francis Group.

Pande, P., Neuman, R., \& Cavanagh, R. (2003). The Six sigma Way :Bagaimana GE, Motorola dan Perusahaan Terkenal lainnya Mengasah KinerjaMereka. Edisi ke-2. Yogakarta: Andi.

Pujawan, I. (2010). Supply chain Management. Edisi Kedua. Surabaya: Guna Widya.

PT Serasi Logistik Indonesia Sub Depo Bandung. (2018). Rekapan ETD (Estimated time Depature). Bandung. 
Wilson, L. (2010). How To Implement Lean Manufacturing. United States: The McGraw-Hill Companies.

Womack, J., \& Jones, D. (2010). Lean thinking: banish waste and create wealth in your. Simon and Schuster.

Yumaida. 2011. Analisis Risiko Kegagalan Pemeliharaan Pada Pabrik Pengolahan Pupuk Npk Granular (Studi Kasus : Pt. Pupuk Kujang Cikampek). (Skripsi). Depok: Universitas Indonesia. 